\title{
Investigation of the clinching process combines with hot stamping process for high-strength steel sheets
}

\author{
Li-Wei Chen ${ }^{a}$, Jian-Ming Huang, and Yuan-Chuan Hsu \\ Department of Mechanical and Computer-Aided Engineering, National Formosa University, Huwei, \\ Yunlin 632, Taiwan
}

\begin{abstract}
The mechanical clinching process combining with hot stamping process for high-strength steel sheets is investigated in this study. Finite elements analysis method and experimental method are applied to analyse the formation of high-strength steel sheet. The connecting strength between two sheets is discussed via the relation between neck thickness and undercut, and the Vickers hardness. The results indicated that the cooling water channels of hot stamping die provided efficiently temperature exchange to control the temperature of sheets. The 15B22 sheet, after being hot stamping process, obtained higher connecting strength than $\mathrm{S} 15 \mathrm{C}$ and $\mathrm{S} 45 \mathrm{C}$. At high temperature, the materials properties of $15 \mathrm{~B} 22$ are similar to that of the S15C. However, due to the hardness of $15 \mathrm{~B} 22$ is higher than that of $\mathrm{S} 15 \mathrm{C}$ and $\mathrm{S} 45 \mathrm{C}$, the undercut is also higher. Hot stamping process means to rapid cooling hot metal, which change the structure from austenite to martensite, so that the hardness will be increased. Hence, the connecting strength of 15B22 is stronger than S15C and S45C.
\end{abstract}

\section{Introduction}

The development of automobile industry growing significantly in the past few decades has further led to global effects of environmental pollution. Lightweight designs of automobile can reduce the emission and also reduce the fuel consumption. However, the traditional manufacture technic is difficult to meet the requirements of safety and lightweight $[1,2]$.

The clinching process is to use a punch and dies to make local deformation of the sheets at cold temperature, and then connects the sheets together. Clinching refers to a mechanical fastening method to join sheet metal without additional components. Clinching was invented by German company TOX PRES-SOTECHNIK GMBH at late 1980s. It was called TOX sheets stamping connecting technology. Such process, which resolved problems happening during welding and riveting, has been certificated by international patent. It is now broadly applied for new materials in automobile industries [3].

\footnotetext{
${ }^{a}$ Corresponding author: liwei@nfu.edu.tw
}

This is an Open Access article distributed under the terms of the Creative Commons Attribution License 4.0, which permits unrestricted use, distribution, and reproduction in any medium, provided the original work is properly cited. 

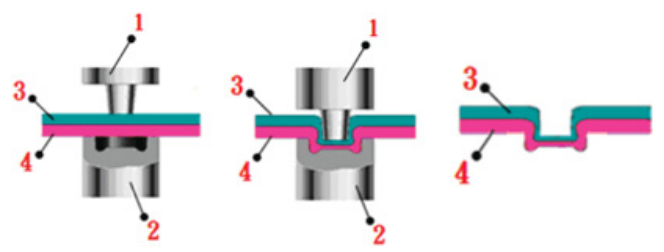

1. punch

2. lower die

3. upper sheet

4. lower sheet

Figure 1. Schematic illustration of the TOX process [9].

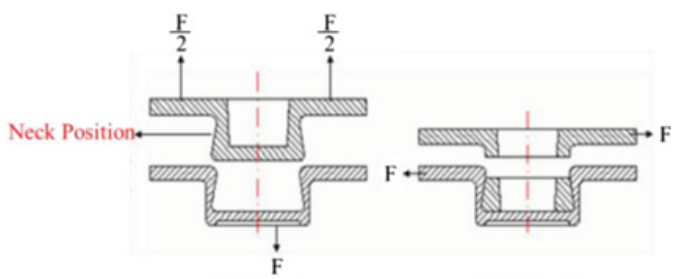

(a) Mode $\mathrm{A}$

(b) Mode B

Figure 2. Two failure modes of the joint, (a) mode A and (b) mode B. [3]

The clinching process takes the advantages of excellent tightness, corrosion proof, simple machining route and high connecting strengths. In addition, it is able to connect different material sheets with low noise pollution and low cost. Such technology is now used in car industry production $[1,3,4]$. The researches about the cold stamping deformation are also being published. For instance, Lee et al. [5] used finite element software to analyse the neck thickness and undercut based on the bottom thickness of die to simulate the connection failure value. The simulation was also compared with actual experiment to prove the software reliability. Y. Abe et al. [6] modify the diameter and shape of die to join the high strength steel sheet and aluminium alloy sheets. The neck thickness and undercut were obtained by experiment. The failure mode and fracture phenomenon were also observed. De Paula et al. [7] use simulation model to modify the detail geometry of die and found that the neck thickness has regular relation with undercut. Jacek and Waldemar's [8] experiment used different clinching method such as single-point and multi-point to observe the connecting strength. Results indicated that the connecting strength became stronger when parallel multi-point was applied, and surely stronger than single-point connection.

The mechanism of joining between material sheets is shown in Fig. 1 [9]. The joining strength includes three types: static strength, fatigue strength and dynamic strength. Static strength can be described by tensile strength and shear strength. There are three possible reasons which may cause failure: firstly, the distortion of materials sheets (Fig. 2a). It will lead connecting point move away from the origin. Secondly, the neck thickness is too thin and fractures form on the material sheets (Fig. 2b). The third reason is combination of first and second type failure; material sheets will break and move away directly [3].

Hot stamping is a novel process to produce ultra-high strength automobile components with high accuracy and low spring back. Hot stamping mainly takes the advantages of high plasticity and ductility, and low yield strength of metals at high temperature. A die is used to deform the metal sheet at high temperature and then quench it. After the hot stamping process, metal sheet is able to obtain martensite structure with accurate size. The tensile strength can be up to $1400 \mathrm{MPa}$. The first step of hot stamping process is heating materials to crystallization temperature (austenite transition temperature), then dwell for few seconds to ensure the austenite structure uniformly. A die with cooling system is subsequently used to form and cool the metal sheets. The cooling temperature is kept above austenite 
region to lower the plastic flow stress, and then increase the formability. After hot stamping, dies were pressured and quenched to confirm the shapes. Finally, ultra-high strength parts with uniformed martensite structure are formed. Compare to cold stamping, hot stamping has the following advantages: 1. Low deformation resistance, high ductility and formability. 2. Lower die and equipment load demand. 3. Simple manufacture processes and short working period. High strength steel sheet is broadly used in modern car industry. It has ultrahigh strength but poor formability. Hot stamping is able to improve the formability of such high strength steel sheet.

A. Turetta et al. [10] used thermal expansion instrument to analyse the cooling experiment for $22 \mathrm{MnB} 5$ steel. The results showed that the martensite phase started rising at $382^{\circ} \mathrm{C}$ and the optimal austenite was at $900^{\circ} \mathrm{C}$. After dwell for 5 minutes, the cooling rate $30^{\circ} \mathrm{C} / \mathrm{s}$ was applied to prevent bainite structure forms. Philipp et al. [11] mentioned the Usibor 1500 steel by hot stamping process is broadly applied in car industry. The non-rebound components can be produced by deforming and quenching Usibor 1500 steel. T. Senuma [12] proved that lightening the weight of car can efficiently reducing the fuel consumption and emission. The result indicates that $10 \%$ lighten of car body lower the usage of fuel up to $3 \% \sim 7 \%$. M. Merklein et al. [13] used thermal simulation testing Gleeble1500 to analyse alloy steel 22MnB5. The obtained material properties were import into finite element data base. Those data will be used as references for simulation. H.S. Liu et al. [14] applied ABAQUS to analyse the duration of deformation, die quenching and spring back for hot stamping process.

A lot of high-strength steel sheets were developed such as 22MnB5, Usibor 1500P and SPFC440 because of the growth of car industry. Also, technique of clinching process is getting mature. Combining clinching process and hot stamping process make high strength structure and lighten steel sheets possible. In this paper, simulation and experiment are both applied to prove the reliability of the clinching process combines with hot stamping process for metal sheets. Finite elements analysis was firstly used during deformation to observe the changes of neck thickness and undercut. The simulation results were also confirmed by experiment. Micro-Vickers hardness was tested to understand the distribution of hardness within the structure. Tensile test aims to analysis the connecting strength after different material sheets joint together. Thermocouple was used to measure and record the die temperature to observe the hot stamping process.

\section{Research method}

\subsection{Finite elements analysis}

Finite elements analysis is an optimize method to designing dies and predict formation parameters. It is also able to solve complex metal plastically deformation. This paper applied DEFPRM-3D to analyse the formation of high-strength steel sheet. Parameters of the simulation setting are shown in Table 1. The materials are S15C, S45C and 15B22, respectively. The joining strength of stamping process is depended on the neck thickness $\left(t_{n}\right)$ and undercut (f).

\subsection{Experimental setup}

The stamping die for mechanical clinching test combining with hot stamping process is designed and the schematic is shown in Fig. 3. The materials used in this research are S15C, S45C and 15B22, respectively. The thickness of steel sheet is $1.4 \mathrm{~mm}$. The sample sizes are shown in Table 2. Clinching process combining with hot stamping process for high-strength steel sheets is an improved technique of cold stamping process. The billets are pre-heated to $900^{\circ} \mathrm{C}$ and dwell for 3 to 5 minutes to form uniform austenitic structure. The die cooling system is water channel inside the punch. Graphite is used as lubricating during deformation process. The neck thickness and undercut are measured by optical image measuring instrument. The simulated billet sizes are gridded and imported into CAD. Then compare the 
Table 1. Parameters of the simulation setting.

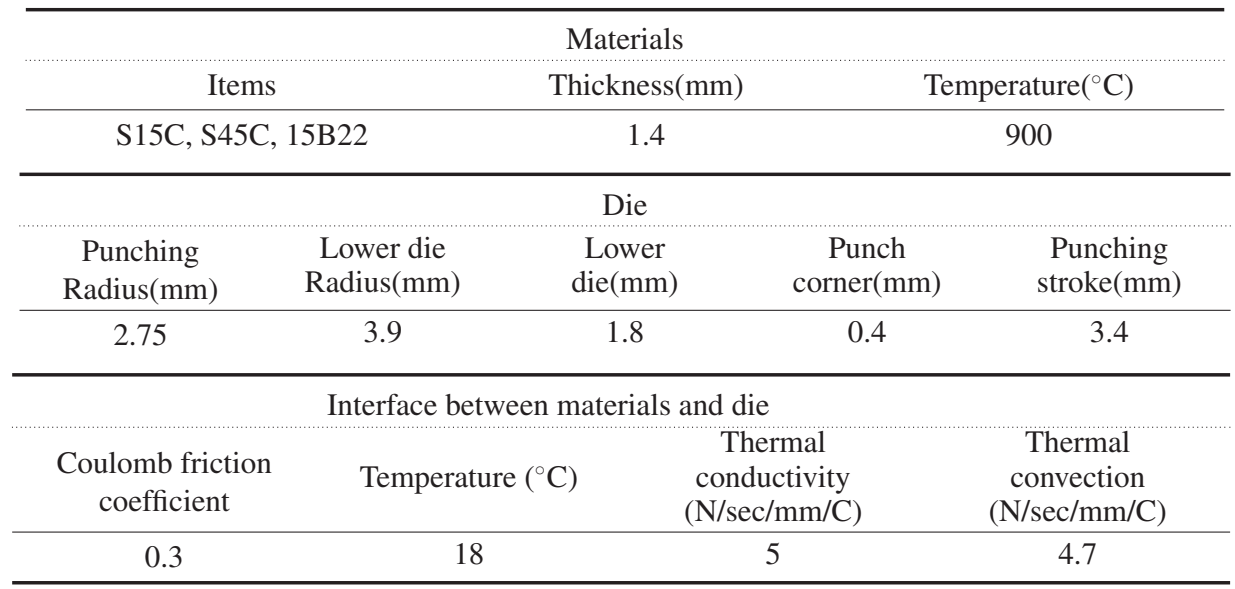
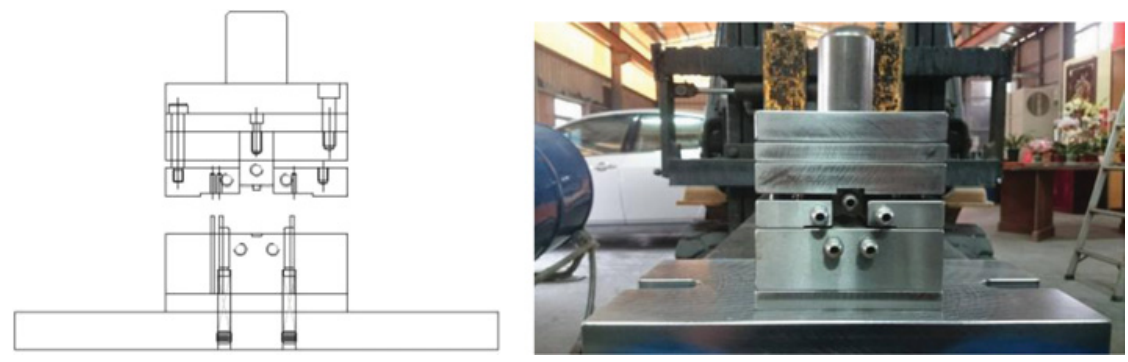

Figure 3. The schematic of stamping die for clinching and hot stamping research.

Table 2. Materials and sample size.

\begin{tabular}{cccc}
\hline Materials & Length $(\mathrm{mm})$ & Width $(\mathrm{mm})$ & Thickness $(\mathrm{mm})$ \\
\hline S15C & & & \\
S45C & 70 & 35 & 1.4 \\
$15 \mathrm{~B} 22$ & & & \\
\hline
\end{tabular}

sizes between simulation and experiment. The hardness is measured by Vickers hardness tester in order to understand the internal structure hardness distribution. The connecting strength of S15C, S45C and $15 \mathrm{~B} 22$ is measured by universal testing machine. TECPEL 318 digital thermocouple is used to measure the die temperature during clinching process and hot stamping process.

\section{Results and discussion}

\subsection{The comparison between simulation and experiment of different material's neck thickness and undercut}

Figure 4 presents schematic of simulation and experimental result of the clinching combines with hot stamping process. The diagram shows similar shapes, which means the simulation fits the experiment. Since simulation was taken under an ideal condition whereas experiment obtained many uncertainties such as feeding rate of materials, the neck thickness and undercut were smaller in experimental data. However, the errors were less than 5\%. Hence DEFORM-3D is suitable for present simulation work. 


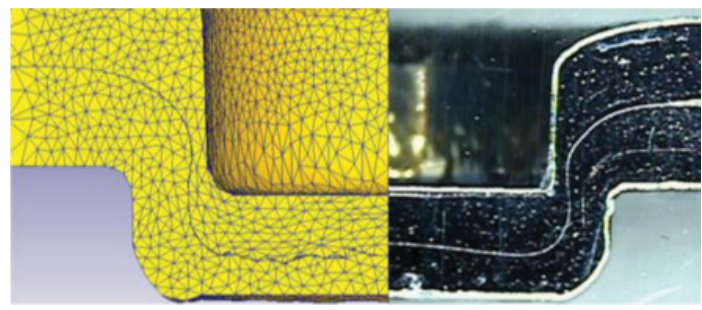

Figure 4. Schematic of simulation and experimental result after clinching process.

Table 3. Simulation and experimental results of neck thickness and undercut.

\begin{tabular}{ccc|ccc}
\hline \multicolumn{3}{c|}{ Neck thickness(mm) } & \multicolumn{4}{c}{ Undercut(mm) } \\
Simulation & Expt. & Error & Simulation & Expt. & Error \\
\hline \multicolumn{6}{c}{ S15C } \\
\hline 0.2284 & 0.217 & $4.99 \%$ & 0.0638 & 0.066 & $3.33 \%$ \\
\hline \multicolumn{6}{c}{ S45C } \\
\hline 0.1874 & 0.1796 & $4.16 \%$ & 0.0668 & 0.0693 & $3.61 \%$ \\
\hline \multicolumn{6}{c}{$15 \mathrm{~B} 22$} \\
\hline 0.219 & 0.210 & $4.11 \%$ & 0.0746 & 0.077 & $3.12 \%$ \\
\hline
\end{tabular}

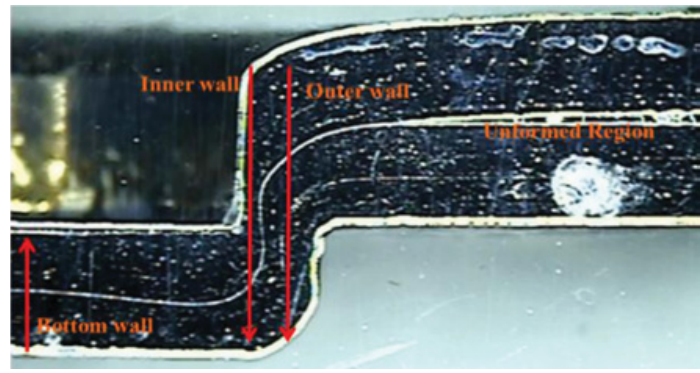

Figure 5. The Vickers hardness measuring area.

The detailed comparison between simulation and experimental results of neck thickness and undercut of S15C, S45C and 15B22 were shown in Table 3. (Data is averaged from 5 samples.)

\subsection{The change of hardness of different materials made by clinching process combines with hot stamping process}

The results show that the hardness at joint is higher than the unformed regions. This is because the billet was compressed by punch. This compression caused plastic formation and the grain structure transformed into fibrous structure. Therefore, higher hardness was measured at this area.

Figure 5 shows the Vickers hardness measuring area and Table 4 shows the detail data of hardness and tensile strength. (Please note that the Vickers hardness of 15B22 in bottom wall is too high to refer to tensile strength table.) Results indicate that bottom wall suffer greatly pressure during processing causes 
Table 4. The detail data of Vickers hardness and tensile strength of S15C, S45C and 15B22.

\begin{tabular}{|c|c|c|c|c|c|}
\hline \multicolumn{2}{|c|}{ Bottom wall } & \multicolumn{2}{|c|}{ Inner wall } & \multicolumn{2}{|c|}{ Outer wall } \\
\hline Hardness & Tensile & Hardness & Tensile & Hardness & Tensile \\
\hline (Hv) & strength $(\mathrm{MPa})$ & (Hv) & strength (MPa) & (Hv) & strength $(\mathrm{MPa})$ \\
\hline \multicolumn{6}{|c|}{ S15C } \\
\hline 208.8 & 663.02 & 174.3 & 559.95 & 165.7 & 532.54 \\
\hline \multicolumn{6}{|c|}{$\mathrm{S} 45 \mathrm{C}$} \\
\hline 391.5 & 1255.42 & 281.5 & 889.23 & 267.3 & 845.38 \\
\hline \multicolumn{6}{|c|}{$15 \mathrm{~B} 22$} \\
\hline 683.3 & - & 455.1 & 1517.52 & 398 & 1305.63 \\
\hline
\end{tabular}

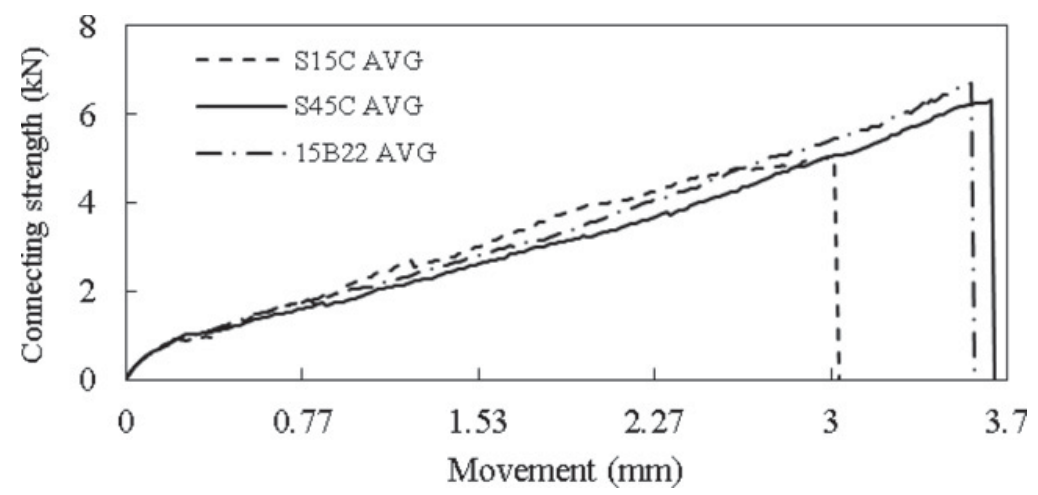

Figure 6. The average connecting strength between two sheets of S15C, S45C and 15B22.

higher hardness than inner and outer wall. The inner wall thickness was also pressurized by punch and cause grain structure became fibrous, therefore the hardness is higher than the outer wall. The outer wall forms when billet flow into die and fill up the cavity, low compression occurred so low hardness was measured.

\subsection{The change of connecting strength of different materials made by clinching process combines with hot stamping process}

The connecting strength between two sheets can be discussed in two parts: 1. relationship between neck thickness and undercut. 2. Vickers hardness. Figure 6 shows the average connecting strength between two sheets of S15C, S45C and 15B22. The neck thickness of S45C is thinner than that of S15C, but the undercut of $\mathrm{S} 45 \mathrm{C}$ is higher than $\mathrm{S} 15 \mathrm{C}$. Therefore, the connecting strength of $\mathrm{S} 45 \mathrm{C}$ is around $1.3 \mathrm{KN}$ higher than S15C and is reached to $6.33 \mathrm{KN}$. The neck thickness of $15 \mathrm{~B} 22$ is between S45C and S15C. However, the undercut of 15B22 is higher than both S15C and S45C forms the highest connecting strength which is $6.71 \mathrm{KN}$. S45C has higher carbon content which gives it higher Vickers hardness than $\mathrm{S} 15 \mathrm{C}$ but still lower than 15B22. Therefore, the connecting strength is $0.4 \mathrm{KN}$ lower than 15B22. 15B22 material has the highest hardness and strength compare to S15C and S45C. Hence, after hot stamping process, 15B22 has the highest hardness, strength and connecting strength. 


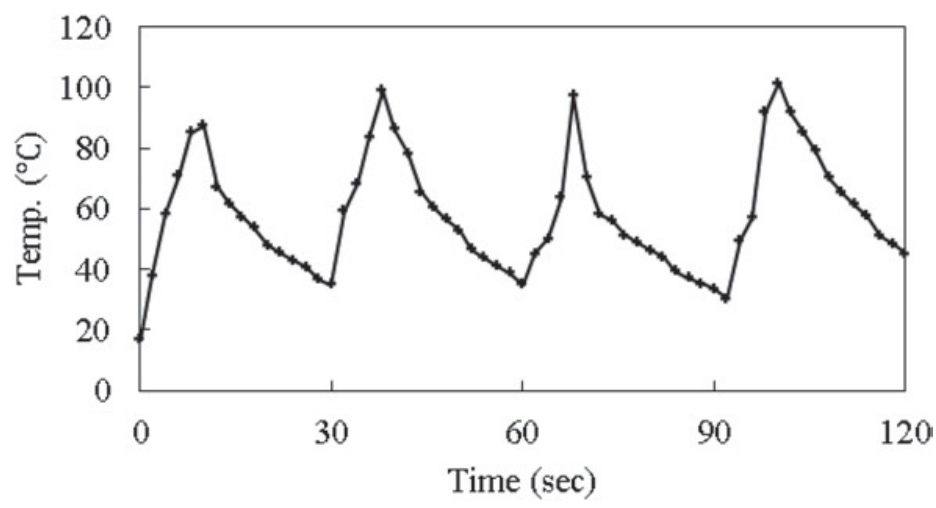

Figure 7. 4 cycle temperature variation of die during hot stamping process.

\subsection{Temperature variation of stamping die during hot stamping process}

The cooling system in the hot stamping die is used to cool the sheets and maintain the die at room temperature. It is important in hot stamping process because high strength steel sheets require rapid cooling quench process to form martensite structure from austenitic structure. Figure 7 shows the thermocouple recorded temperature variation of die during hot stamping process. The curve represents that hot stamping process took about 10 seconds to deform and 20 seconds to quench until the temperature declined to room temperature. The 4 cycles temperature variations illustrate that the maximum temperature of die during hot stamping process was $100^{\circ} \mathrm{C}$. Moreover, within the next 20 seconds of quenching, the cooling system is able to cool the die to room temperature. Please note that the temperature measure point is few millimeter away from punch.

\section{Conclusions}

In this investigation, DEOFRM-3D was used to analyse the neck thickness and undercut. The comparison between simulation and experimental was presented to prove the reliability of software. Several measurements were taken such as micro Vickers hardness and tensile strength. The materials used in the investigation were S15C, S45C and 15B22. The changes in hardness and the connecting strength between two sheets for each material were recorded. The cooling system was also examined to observe the temperature variations. The results are summarized as below:

1. Statistics results show that the errors between simulation and experiment data were only less than $5 \%$ in neck thickness and undercut.

2. The connecting strength between two sheets can be discussed by two parameters: 1. the relationship between neck thickness and undercut. 2. The Vickers hardness. S15C has low carbon content causes the low hardness and strength after deformation. Therefore, the neck thickness is thinner but undercut is high. S45C has higher carbon content so the hardness is higher than $\mathrm{S} 15 \mathrm{C}$ but lower than the 15B22. Compare to S15C, the neck thickness is thinner but higher the undercut. 15B22 has similar properties with S15C at high temperature, therefor it is also easy to deform. Also the neck thickness is thicker than S45C.The micro structure of 15B22 shifts from austenite to martensite after hot stamping and quenching processes. Therefore, the highest hardness is formed after deformation.

3. A high-strength steel sheet made by hot stamping process requires rapid cooling of quenching process in order to form the micro structure from austenite to martensite. Hence, cooling system takes an important role during this manufacture process. Nevertheless, the variation 


\section{MATEC Web of Conferences}

trend of temperature present the cooling system is capable to control the temperature during the manufacture process.

\section{References}

[1] N. Ning, K.J. Ouyang, Y. Zhang, Z.Y. Qiao, C.C. Tao, F.P. Li, J. Mater. Process. Technol, 137, Pages 159-163 (2003)

[2] R. Neugebauer, C. Kraus, S. Dietrich, CIRP Annals-Manuf. Technol., 57, Pages 283-286 (2008)

[3] J.P. Varis, J. Lepistö, Thin-Walled Structures, 41, Pages 691-709 (2003)

[4] V. Hamel, J.M. Roelandt, J.N. Gacel, F. Schmit, Computer \& Structures, 77, Pages 185-200 (2000)

[5] C.J. Lee, J.Y. Kim, S.K. Lee, D.C. Ko, B.M. Kim, Mater. Des., 31, Pages 1854-1861 (2010)

[6] Y. Abe, K. Mori, T. Kato, J. Mater. Process. Technol., 212, Pages 884-889 (2012)

[7] A.A de Paula, M.T.P Aguilar, A.E.M Pertence, et al., J. Mater. Process. Technol., 182, Pages 352-357 (2007)

[8] Jacek Mucha, Waldemar Witkowski, Thin-Walled Structures, 66, Pages 39-49 (2013)

[9] http://www. tox-en. com/company.html - The Company TOX Pressotechnik

[10] A. Tueretta, S. Bruschi, A. Ghiotti, J. Mater. Process. Technol., 177, Pages 396-400 (2006)

[11] P. Hein, J. Wilsius, Steel Research International, 79, Pages 85-91 (2008)

[12] T. Senuma, ISIJ International, 41, Pages 520-532 (2001)

[13] M. Merklein, J. Lechler, J. Mater. Process. Technol., 177, Pages 452-455 (2006)

[14] H.S. Liu, Z.W. Xing, J. Bao, B.Y. Song, J. of Mater Eng. Perform., 19, Pages 325-334 (2010) 